\title{
A COCONSTRUÇÃO dE SENTIDOS E A IMAGINAÇÃO EM PRÁtICAS DE LEITURA ANCORADAS NOS GÊNEROS TEXTUAIS:
}

\author{
ANÁLISE DE UMA PROPOSTA PARA 0 4 ANO DO ENSINO FUNDAMENTAL
}

\begin{abstract}
Aline Salucci Nunes ${ }^{1 *}$
Carolina Scali Abritta ${ }^{2 * *}$

Resumo:A partir de uma perspectiva pragmática da linguagem, inspirado pelas teorias de letramentos (KLEIMAN, 2007; STREET, 2014 [1995]) e gêneros textuais (MARCUSCHI, 2008; BHATIA, 2001 [1997]; BAKHTIN, 2011; SCHNEUWLY e DOLZ, 2011 [2004]); este artigo pretende promover uma análise da fala-em-interação em sala de aula. A atividade de leitura posta em andamento na aula abriu espaço para investigar como o processo de coconstrução de sentidos sobre um texto próprio do gênero jornalístico desperta a imaginação e amplia o trabalho com o texto escrito. Os resultados mostraram que uma proposta de aula, inspirada na arte de brincar com a produção de sentidos de um texto, conseguiu um engajamento maior das crianças; não reduziu a prática de leitura a exercícios de "copiar e colar", e permitiu a coprodução de significados, orientando a imaginação de modo a estimular o processo de ensino e aprendizagem.
\end{abstract}

Palavras-chave: Fala-em-interação. Coconstrução de sentidos. Imaginação. Gêneros textuais. Letramento.

Introdução

A visão formalista da linguagem que entende as palavras como portadoras do sentido das coisas está em falência e cede a vez para uma "'era da imaginação' em que a analogia, a metáfora, a metonímia deixam o desprestígio para entrar na ordem do dia" (MARCUSCHI, 2007, p. 87). Nessa nova era, os sentidos das palavras são apenas apontados pelas formas linguísticas às quais estão atrelados. A produção de significados passa a ser vista como um processo de coconstrução situado a depender das intersubjetividades produzidas localmente. E o conhecimento é, então, entendido como construído através da interação do sujeito com os outros, a partir das experiências sensoriais, culturais e sociais, tornadas relevantes localmente.

No contexto de sala de aula, em que esta pesquisa está situada, a prática de leitura leva em conta as múltiplas experiências e práticas sociais e culturais emergentes no processo de

1 Mestra em Letras pela UERJ - FFP. Professora da rede municipal de ensino de Itaboraí. alinesalucci@yahoo.com.br.

${ }^{2}{ }^{*}$ Doutora em Letras pela PUC Rio. Professora adjunta da Universidade do Estado do Rio de Janeiro. carolabritta30@gmail.com. 
coconstrução de sentidos. Nesse sentido, olhamos para o fenômeno da compreensão textual sob outro enfoque - uma vez que, como postulado por Koch (2014, p. 30), "o sentido não está no texto, mas se constrói a partir dele, no fluxo de uma interação" - e abrimos caminho para que, através da imaginação, os alunos sejam participantes ativos na construção conjunta de conhecimento.

Sob a ótica apresentada, desenvolvemos, durante o ano de 2015, uma pesquisa de mestrado de natureza intervencionista que tomou como seu campo uma turma de 4 o ano do ensino fundamental, em uma escola da rede pública de ensino, localizada no município de Itaboraí. 0 objetivo precípuo desse estudo era contribuir para o melhor desenvolvimento da competência leitora dos alunos recém-saídos do ciclo de alfabetização.

Para tanto, formulamos uma sequência de atividades situadas numa perspectiva de multiletramentos, considerando, portanto, as variadas práticas letradas das quais os alunos participam dentro e fora da escola. Parte desse trabalho intervencionista na sala de aula deu-se com o gênero jornalístico. O que se pôde constatar, no que toca a essa parte, especialmente, conforme veremos adiante, foi a importância do casamento entre uma perspectiva linguística interacional na abordagem do gênero escolhido para ampliar a capacidade de coconstrução de sentido das crianças, na medida em que esta foi capaz de fomentar a imaginação dos meninos e meninas naquele cenário de sala de aula.

Nesse sentido, este artigo pretende oferecer um pequeno mapa do processo de coconstrução de sentido/conhecimento sobre um objeto textual próprio do gênero jornalístico utilizado em uma aula de língua portuguesa. Começamos, porém, mostrando os construtos teóricos fundadores do nosso plano de intervenção.

1. A imaginação na sala de aula e a coconstrução de conhecimento: como acontecem e como as percebemos

Inspirada numa filosofia pragmática de linguagem, a presente pesquisa entende que a linguagem se constrói no "fluxo das práticas e costumes de uma comunidade linguística, histórica e culturalmente determinada" (MARTINS, 2011, p. 442). Ou seja, a linguagem, assim como a realidade e o conhecimento, é uma construção e não um dado de uma realidade pronta e acabada. Nesse mesmo sentido, assumimos com Wittgenstein (1999 [1953]) que a significação, como parte dessa realidade inacabada, se constrói no uso. E isto significa que "toda a produção de significação está ligada a uma atividade coletivamente conduzida" (MARCUSCHI, 2007, p. 85). Entendemos que não há uma significação fixa a qual determinadas palavras representam, mas significações possíveis que variam de acordo com contextos e objetivos específicos, uma vez que "a maneira como nós dizemos 
aos outros as coisas é decorrência de nossa atuação intersubjetiva sobre o mundo e da inserção sociocognitiva no mundo em que vivemos" (MARCUSCHI, 2007, p. 126). Há aqui, então, uma ruptura com um paradigma representacionista da linguagem.

Para explicar essa ruptura na relação entre linguagem e realidade, Fauconnier e Turner (2002) distinguem dois momentos: a Era da Forma, que remonta à Antiguidade Clássica, e a Era da Imaginação, que tem sido construída desde o final do século XX. Segundo Marcuschi (2007), a era da forma, caracterizada por uma visão cartesiana de pensamento como representação da realidade e de linguagem como representação do pensamento, está em falência e "dá agora a vez a uma 'era da imaginação'” (p. 87). O conhecimento é, portanto, construído socialmente, levando-se em conta o contexto, assim sendo, apesar de a forma ser necessária, ela não é, em absoluto, "única nem autônoma na produção de sentidos" (MARCUSCHI, 2007, p. 86).

Acreditamos que a contribuição dessa mudança paradigmática esteja, porém, muito além de sua abordagem instável do processo de significação, ela chega até uma visão de linguagem que considera o contexto da atividade que ela constitui e na qual é constituída. Essa teoria parece dar conta de unir linguagem e atividade como práticas de construção de conhecimento na e através da interação na medida em que apresenta a linguagem como atividade linguística. Segundo Glock (1998, p. 229), "as atividades linguísticas estão interligadas com nossas práticas não linguísticas" e encontram-se imersas em nossas formas de vida, "nas práticas gerais de uma comunidade linguística". Essa visão é corroborada por Harré e Gillett (1999, p. 25), quando afirmam que "uma pessoa não é uma conhecedora ou intérprete isolada do mundo, mas está engajada com outras em atividades práticas, cerimoniais e comunicativas que se constituem formas de vida, nas quais a linguagem é ensinada e aprendida".

Os processos que envolvem o uso das palavras, seja para nomear objetos, seja para mediar a relação de sentido que essas palavras adquirem nas atividades culturais e sociais no dia a dia das pessoas, Wittgenstein (1999 [1953]) denomina “jogos de linguagem” (p. 30).

Em suma, o que se pode depreender da perspectiva wittgensteiniana acerca da linguagem é que não se trata de uma estrutura fixa, com regras fixas pré-estabelecidas, mas se constitui de inúmeras formas de comunicar, que mantém entre si relações de semelhança, sendo cada uma dessas formas um jogo de linguagem.

O que significa dizer que só é possível perceber se um conceito foi construído quando usado adequadamente nos contextos apropriados. Nos termos de Koch e Cunha-Lima (2011):

Entender o uso do significado de uma sentença (ou entender o funcionamento da linguagem em geral) exigiria observar essa língua em funcionamento, observar como os falantes constroem sentido com ela, como se engajam em atividades 
usando a língua como forma de mediação. Além disso, seria necessário considerar o contexto mais imediato do uso da língua e as relações desses usos linguísticos com as condições mais gerais de produção, tais como as visões de mundo e as práticas culturais e sociais dos falantes (p. 287).

Os processos de construção de sentido devem estar, portanto, associados à maneira como seus praticantes vivem, interagem e enxergam o mundo, ou seja, às formas de vida, e, assim como os outros jogos de linguagem, precisam ser vivenciados. Essa competência se adquire na prática: "seguir uma regra, fazer uma comunicação, dar uma ordem, jogar uma partida de xadrez são hábitos (costumes, instituições). Compreender uma frase significa compreender uma linguagem. Compreender uma linguagem significa dominar uma técnica." (WITTGENSTEIN, 1999 [1953], p. 92).

A construção do conhecimento se dá à medida que é posto em prática nos jogos de linguagem, tanto na interação via texto, quanto na interação face a face. Assim, em uma conversa, por exemplo, cada tomada de tuno corresponde a um "lance no jogo" (MARTINS, 2000, p. 37) que são embasados em um conjunto de conhecimentos e experiências partilhado pelos falantes (KOCH e CUNHA-LIMA, 2011, p. 281).

A análise de como os participantes desta pesquisa coconstruíram conhecimento durante a prática de leitura teve seu foco na interação pela fala, em ambiente natural de produção, e guiou-se pelo contexto sequencial da fala-em-interação, inspirada na Análise da Conversa Etnometodológica.

A fala-em-interação, objeto de estudo da ACE, é organizada por um sistema de tomada de turnos que tem na conversa cotidiana sua pedra fundamental (SACKS, SCHEGLOFF e JEFFERSON, 2003 [1974]). Essa organização se estende, com algumas modificações, a outros sistemas de troca de falas, como aqueles que constituem uma conversa institucional, atividade orientada para uma meta (GARCEZ, 2002). Numa sala de aula, a interação, que é institucional, acontecerá de modo que satisfaça ao objetivo planejado para a aula. Nesse cenário, normalmente, a troca de turnos é organizada pelo professor, que geralmente utiliza uma sequência descrita por Sinclair e Coulthard (1975) como Iniciação-resposta-Avaliação (IRA), em que "o turno de iniciação é muitas vezes uma pergunta cuja resposta já é conhecida por quem pergunta" (GARCEZ, 2006).

A partir desses fundamentos, pretendemos mostrar como o trabalho com o gênero textual jornalístico contribuiu para a coconstrução de conhecimento durante a atividade de leitura.

\section{Letramentos e gêneros textuais nas práticas escolares}

De acordo com Street (2014 [1995], p. 154) "todo letramento é aprendido num contexto específico de um modo particular e as modalidades de aprendizagem, as relações sociais dos estudantes com o professor são modalidades de socialização e aculturação". 
A concepção de letramentos como práticas sociais de leitura e escrita, que dá sustentação a este trabalho, inspira-se no modelo ideológico de letramento - assim denominado por Street (2014 [1995]) - que abrange questões culturais, de identidade e de relações sociais de poder entre os grupos envolvidos nessas práticas, em contraposição ao modelo autônomo, criticado por esse mesmo autor, que, de forma simplificada, se reduz às capacidades de uso da língua escrita desvinculado do contexto social.

Nessa perspectiva plural, é possível dizer que nossos alunos estão inseridos em grupos que participam de múltiplas práticas de letramento, valorizadas ou não, dentro e fora da escola. Por essa razão, concordamos com Kleiman (2007) que considera pertinente a assunção dos "múltiplos letramentos da vida social como o objetivo estruturante do trabalho escolar em todos os ciclos" ( $p$. 4).

Rojo denomina multiletramentos aqueles caracterizados pela diversidade cultural de produção e circulação de textos e pela diversidade de linguagens que os constituem. Nesse sentido, multiletramentos é um conceito que abrange a "multiculturalidade característica das sociedades globalizadas e a multimodalidade de textos por meio dos quais a multiculturalidade se comunica e se informa" (ROJO, 2012, p. 13).

$\mathrm{Na}$ interação cotidiana, os indivíduos realizam suas escolhas linguísticas de acordo com seus objetivos ou suas necessidades situadas localmente. Tais escolhas não são aleatórias, mas se dão de acordo com determinados padrões sociocomunicativos. Cavalcante (2014, p. 44-45) explica que esses "padrões sociocomunicativos que se manifestam por meio de textos de acordo com as necessidades comunicativas específicas" são denominados gêneros discursivos ou gêneros textuais.

A multiplicidade das práticas letradas demanda o domínio de diferentes gêneros textuais que se concretizam nos textos presentes na vida das pessoas dentro e fora da escola. Desse modo, acreditamos que uma proposta organizada em torno dos gêneros textuais de diversas esferas, alocados em variados suportes enriquece a prática e proporciona novas aprendizagens.

Os gêneros textuais ou do discurso têm recebido atenção especial desde a Antiguidade, concentrando-se na retórica e na literatura. Marcuschi (2008) observa que, no Ocidente, a análise dos gêneros literários inicia-se com Platão e continua até os primórdios do século XX. No entanto, com o surgimento da linguística, como ciência da linguagem, outras perspectivas se incorporam ao estudo dos gêneros. Swales, citado por Marcuschi (2008, p. 147), afirma que "hoje, gênero é facilmente usado para referir a uma categoria distintiva de discurso, de qualquer tipo, falado ou escrito, com ou sem aspirações literárias". 
O conceito de gêneros do discurso desenvolvido por Mikhail Bakhtin (1979) ${ }^{3}$, que está situado em uma concepção interacionista de linguagem, é explicado sinteticamente por Schneuwly (2011 [2004], p. 23) como "tipos relativamente estáveis de enunciados" que se caracterizam por seu conteúdo temático, estilo e construção composicional e cuja escolha é determinada "pela esfera, as necessidades da temática, o conjunto de participantes e a vontade interativa ou intenção do locutor".

O que determina o gênero é sua função e não sua forma. A indagação feita por Bhatia (2001, p. 102) sobre "por que os membros de comunidades discursivas específicas usam a língua da maneira como fazem" indica que o estudo de gêneros não deve restringir-se a aspectos estruturais ou formais, mas considerar fatores socioculturais e cognitivos visando ao esclarecimento dos "propósitos comunicativos da comunidade discursiva em questão" e das estratégias empregadas para atingi-los (BHATIA, 2001, p. 102).

Acerca do propósito comunicativo, Biasi-Rodrigues e Bezerra (2012, p. 235) explicam que "tem a ver com aquilo que os gêneros realizam na sociedade". Assim, um gênero pode realizar mais de um propósito comunicativo: a "intenção particular" do produtor ou controlador da produção e circulação do gênero, e os "propósitos socialmente reconhecidos".

O propósito comunicativo, portanto, não será algo imanente no texto como tal, visto que se trata sempre de um processo de construção social desse propósito ou propósitos, nem será uma realidade meramente psicológica, definível como "intenção do autor", pois seria imperativo questionar essa onipotência do autor sobre o texto e sua recepção na sociedade (BIASI-RODRIGUES; BEZERRA, 2012, p. 236).

$\mathrm{Na}$ teoria bakhtiniana, os gêneros do discurso aparecem distinguidos como primários (simples) - "que se formaram nas condições da comunicação discursiva imediata” (BAKHTIN, 2011, p. 262) ou espontânea, como um diálogo cotidiano -, e secundários (complexos) - "que surgem nas condições de um convívio cultural mais complexo e relativamente muito desenvolvido e organizado (predominantemente o escrito)" (BAKHTIN, 2011, p. 262) -, a partir da incorporação e reelaboração de diversos gêneros primários. Em suma, o que é possível depreender da divisão proposta por Bakhtin é que a partir das interações espontâneas cotidianas as crianças passam a dominar os gêneros primários com base nos quais, em um contexto novo de aprendizagem, tal qual o escolar, poderão desenvolver os gêneros secundários (SCHNEUWLY, 2011 [2004]).

3 A obra Estética da criação verbal, publicada postumamente em 1979, na Rússia, teve sua primeira publicação brasileira em 1992, sendo relançada em 2003, pela editora Martins Fontes. Neste artigo, foi utilizada a 6a edição, datada de 2011. 
A teoria de gêneros de Bakhtin alimenta o modelo defendido pela Escola de Genebra, particularmente por Bronckart, Dolz e Schneuwly, que sob uma perspectiva interacionista e sociodiscursiva, visam à interação com o gênero no ensino de língua materna. Nessa linha, gênero é entendido "como um instrumento semiótico constituído de signos organizados de maneira regular" (DOLZ e SCHNEUWLY, 2011 [2004], p. 143) que possibilita a ação discursiva. Nas situações de uso e de aprendizagem, Dolz e Schneuwly utilizam a metáfora do megainstrumento ${ }^{4}$ para explicar que os gêneros textuais também representam o meio pelo qual se tornam conhecidos, pois, ao mesmo tempo, fornecem "um suporte para a atividade, nas situações de comunicação, e uma referência para os aprendizes" (DOLZ e SCHNEUWLY, 2011 [2004], p. 65).

Assim sendo, acreditamos que, para que o aluno aprimore suas práticas de linguagens oral e escrita, seja necessário dominar esses instrumentos, os gêneros, que para Bronckart (2010 [2007], p. 79, tradução minha) consistem "no produto de configurações de eleição entre algumas possibilidades momentâneas 'cristalizadas' ou estabilizadas pelo uso" ${ }^{5}$, oriundas da necessidade de adaptação das formações sociodiscursivas às atividades de comunicação situadas das quais os sujeitos da interação participam.

Dentro e fora da escola, as ações discursivas, que são os gêneros, se concretizam nos textos, e é a competência metagenérica - termo cunhado por Koch (2004) e retomado por Koch e Elias (2014) - que possibilita aos indivíduos interagir da forma que Ihes convêm, de acordo com a prática social na qual estão envolvidos. No que concerne à prática de leitura, essa competência permite que se compreendam os gêneros textuais produzidos, tornando-se assim fundamental, como esclarecem as autoras, para a tarefa de produção de sentidos (Koch e Elias, 2014, p. 103).

Acreditamos que um trabalho com a leitura a partir dos gêneros textuais favoreça práticas de letramento que partam de textos que de fato circulam na sociedade. Nesse sentido, trabalhamos para oportunizar aos alunos o contato com gêneros diversos no intuito de promover variadas práticas de letramento.

Selecionamos para este artigo um pequeno recorte da sequência de atividades desenvolvida com a turma de 4ㅇ ano envolvida na pesquisa. Na atividade que será apresentada, trabalhamos com uma reportagem, a partir da qual os alunos coconstruíram conhecimento e tiveram sua imaginação despertada.

4 “Poderíamos construir uma outra metáfora: considerar o gênero como um 'megainstrumento', como uma configuração estabilizada de vários subsistemas semióticos (sobretudo linguísticos, mas também paralinguísticos), permitindo agir eficazmente numa classe bem definida de situações de comunicação". (DOLZ e SCHNEUWLY, 2011 [2004], p. 25).

$5 \quad 0$ texto em língua estrangeira é: "los géneros de textos son el producto de configuraciones de elección entre algunas posibilidades monmetáneamnte 'cristalizadas' o estabilizadas por el uso". 


\section{A atividade de leitura com gênero jornalístico}

No intuito de esclarecer como a atividade de leitura que será analisada neste artigo aconteceu, explicamos que a escolha da reportagem em questão se justifica em razão de noticiar um fato socialmente relevante cujo tema satisfazia ao interesse demonstrado pela turma por assuntos relacionados ao espaço. Assim, em aulas anteriores o tópico já havia sido explorado e amplamente discutido, a partir de diferentes gêneros textuais.

A atividade com o texto jornalístico fez parte de uma sequência de atividades planejada para acontecer em uma aula de 120 minutos, que visava à prática de leitura através de diferentes modalidades textuais. Desse modo, optamos por manter os três momentos rotineiros das aulas de língua portuguesa denominados roda de conversa, roda de leitura e momento do registro.

Desta feita, antecedendo a reportagem, foi organizado um trabalho com um texto imagético, a fim de motivar a participação das crianças e ativar conhecimentos prévios. Nesse sentido, a roda de conversa contou com a projeção de uma imagem em que o Sol aparecia encoberto pelo planeta Terra.

A roda de leitura se baseou em uma reportagem a respeito do 50 o aniversário da primeira viagem do homem ao espaço - texto utilizado na atividade analisada neste artigo - e um trailer do filme Gagarin, o primeiro no espaço.

Nas atividades desenvolvidas nesse momento, realizamos com os alunos uma tarefa de leitura compartilhada, que, de acordo com Solé (1998, p. 120), "tem como objetivo ensinar as crianças a compreender e a controlar sua compreensão". Por entender que o sentido não é imanente ao texto, mas precisa ser construído, propomos que a tal tarefa seja atribuído o objetivo de mediar o processo de coconstrução de conhecimento.

No momento do registro, os alunos tiveram a oportunidade de apresentar um resumo oral dos sentidos que haviam construído a partir dos textos lidos.

Após os três momentos habituais, introduzimos um objeto de aprendizagem em formato de jogo de computador e a aula foi encerrada após três partidas acaloradas do jogo que tinha como objetivo encontrar astronautas perdidos no espaço, refazendo seu percurso através das pistas fornecidas a cada etapa.

Isto posto, a fim de iniciar a atividade com o gênero jornalístico, distribuímos as cópias da seguinte reportagem, que também apareceu projetada na parede. 


\section{Primeira viagem do homem ao espaço faz 50 anos}

Yuri Gagarin deu a volta na órbita da Terra em 89 minutos em 12 de abril de 1961

DoR7 publicado em 12/04/2011 às $05 \mathrm{~h} 55$

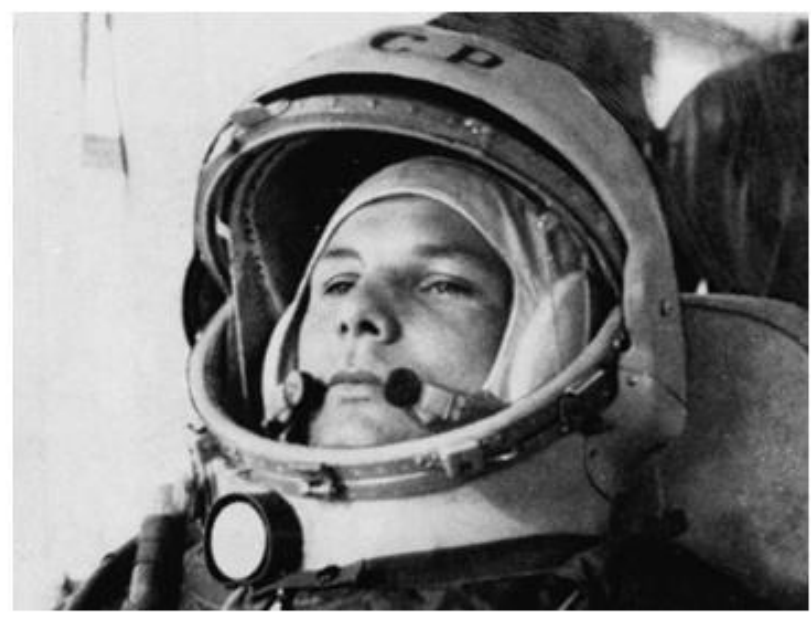

Há 50 anos, aos 27 anos de idade, Yuri Alekseievitch Gagarin se tomava o primeiro homem no espaço. Gagarin entrou para a história no dia 12 de abril de 1961, ao dar a voltana órbita da Terra em 89 minutos - o tempo total da viagem foi de 1 hora e 48 minutos - a bordo da cápsula Vostok. Ele estava sendo treinado como um cosmonauta havia 1 ano e 29 dias, mas, apenas nos dois últimos meses, soubera que seria o primeiro homem a chegar ao espaço.

Durante o voo, o cosmonauta disse duas frases que entrariam para a história. - A Terra é azul.

[...]

- Olhei para todos os lados, mas não vi Deus.

Figura 1 - Reportagem

Para que se compreenda como ocorreu o processo de coconstrução de sentidos sobre o texto disposto acima, apresentamos a seguir uma análise de quatro excertos da aula, que foi gravada em áudio e transcrita com base no modelo de convenções proposto Jefferson (2004) ${ }^{6}$.

\section{Análise dos dados}

No excerto analisado a seguir, Aline oferece pistas sobre o assunto que estará em voga durante a leitura do texto.

EXCERTO 1: "a gente vai falar $(1,2)$ sobre uma pessoa $(1,0)$ a primeira $(0,9)$ que conseguiu $(0,9)$ sair daqui do planeta da onde a gente tá $(1,0)$ e ir pro espaço"

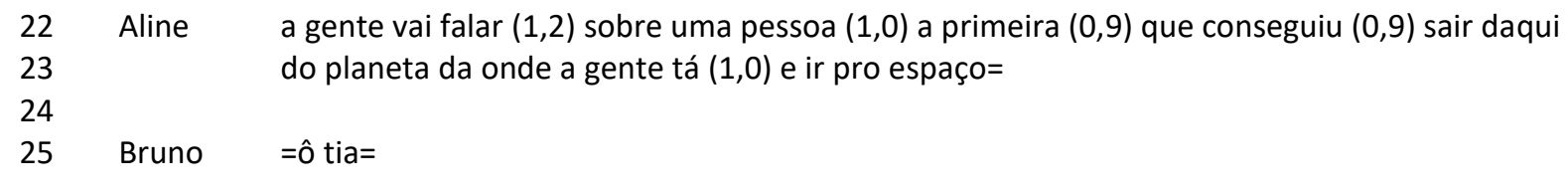

6 Uma versão sintética do modelo de transcrição Jefferson está em LODER, Letícia Ludwing. O modelo Jefferson de transcrição: convenções e debates. In: LODER, Letícia Ludwing; JUNG, Neiva Maria. (Org.) Fala-eminteração social: introdução à Análise da Conversa Etnometodológica. Campinas, SP: Mercado das Letras, 2008, p.127-161. 


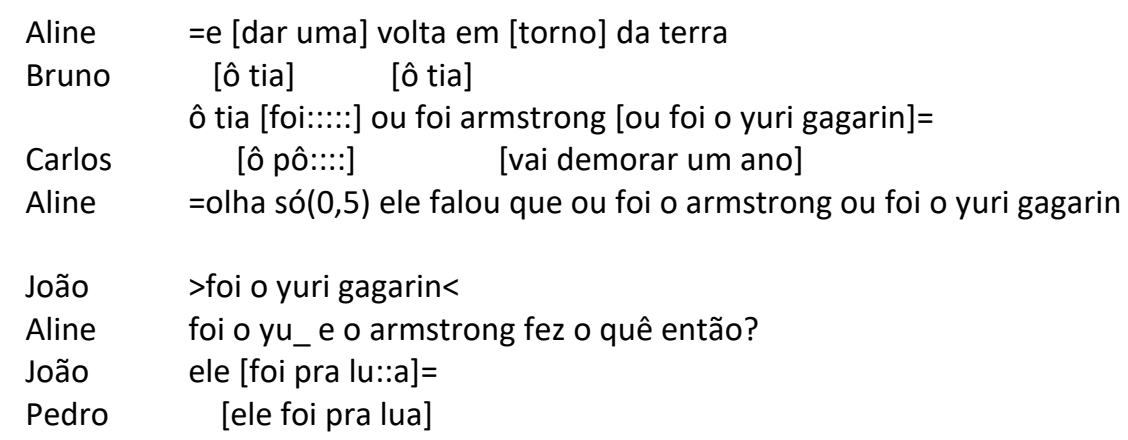

No intuito de ativar conhecimentos prévios, Aline apresenta a temática da reportagem nas linhas 22 a 24 : "a gente vai falar $(1,2)$ sobre uma pessoa $(1,0)$ a primeira $(0,9)$ que conseguiu $(0,9)$ sair daqui do planeta da onde a gente tá $(1,0)$ e ir pro espaço=".

Verificamos que sua fala abre espaço para a participação dos alunos através da expressão "a gente vai falar". Tal abertura é percebida por Bruno, que tenta lhe tomar o turno nas linhas 25: "=ô tia=" e 27: "[ô tia][ô tia]", no entanto, sua hesitação em responder de imediato parece indicar que espera por pistas mais esclarecedoras.

Apenas após Aline completar sua fala, na linha 26: "=e [dar uma] volta em [torno] da terra" é que Bruno se arrisca, anunciando o novo tópico: "ô tia [foi:::::] ou foi armstrong [ou foi o yuri gagarin]=" (linha 28).

Aline, então, lança as hipóteses levantadas por Bruno para que toda a turma possa tentar resolver: "=olha só(0,5) ele falou que ou foi o armstrong ou foi o yuri" (linhas 30 e 31) e, dessa vez, quem confirma a hipótese de Bruno é João, na linha 32: ">foi o yuri gagarin<".

A turma segue trabalhando coletivamente para atividade de construção de sentidos, como podemos observar na sequência da troca de turnos, em que Aline questiona sobre a outra personagem mencionada por Bruno: "foi o yu_ e o armstrong fez o quê então?" (linha 33) e alguns meninos respondem em coro: "ele [foi pra lu::a]=" (João, linha 34); “[ele foi pra lua]" (Pedro, linha 35).

A seguir, já com o texto em mãos, as crianças demonstram como se apoiam na superfície textual para coconstruírem significados.

EXCERTO 2: "cosmonauta <aqui ó aqui ó t'aqui t'aqui depois ó"

$\begin{array}{lll}47 & \text { Carlos } & \begin{array}{l}\text { cosmonauta <aqui ó aqui ó t'aqui t'aqui depois ó }(0,5) \text { ó ((Carlos começa a ler em voz alta)) } \\ 48\end{array} \\ 49 & & \begin{array}{l}\text { sendo treinado como cosmonauta havia um ano e vinte e nove dias }{ }^{\circ} \text { mas } \\ \text { dois ]últimos meses }\end{array} \\ 50 & & \text { [apenas nos } \\ 51 & \text { João } & \text { [oi tia cosmonauta] } \\ 52 & \text { Aline } & \text { is::::so cosmonauta }(1,5) \text { cês já tinham visto alguma foto do yuri gagarin? } \\ 53 & & \text { não } \\ 54 & \text { João } & \text { não: nenhuma foto }(0,5) \text { essa aqui é a foto dele }(0,5) \text { com a roupa de cosmonauta ((alunos } \\ 55 & \text { Aline } & \text { conversam por } 3 \text { segundos)) }\end{array}$


O segundo excerto, extraído de uma situação de interação que ocorreu durante a atividade de leitura, revela o momento em que Carlos descobre uma nova palavra, diferente de astronauta, para se referir à pessoa que pilota uma nave espacial ou nela é tripulante.

Nas linhas 47 a 50, Carlos revela sua descoberta: "cosmonauta" e aponta: "<aqui ó aqui ó t'aqui t'aqui depois ó $(0,5)$ ó" para o trecho do texto no qual se apoiou para fazê-la: "((Carlos começa a ler em voz alta)) sendo treinado como cosmonauta havia um ano e vinte e nove dias ${ }^{\circ}$ mas [apenas nos dois ]últimos meses"”.

João, na linha 51: "[oi tia cosmonauta]", revela seu interesse em participar da descoberta, em fala sobreposta a de Carlos - marcada na transcrição pelos colchetes.

Podemos perceber o entusiasmo de João através de sua fala sublinhada, indicando um volume de voz mais alto que o normal. Fato que nos leva a crer que o jogo de linguagem motivado pela atividade de leitura segue animado.

Ao validar a participação das crianças, nas linhas 52 e 53: "is::::so cosmonauta $(1,5)$ cês já tinham visto alguma foto do yuri gagarin?", Aline tem o cuidado de inserir o novo termo ao repertório dos meninos e meninas, assim faz referência à fotografia utilizando a palavra recém-descoberta em uma nova construção: "não: nenhuma foto $(0,5)$ essa aqui é a foto dele $(0,5)$ com a roupa de cosmonauta" (linhas 55 e 56), mostrando, através do uso, a significação atribuída à palavra, enfatizando, também, com o aumento do volume da voz, a parte de sua fala em que o novo termo aparece.

No excerto seguinte, Aline trabalha um aspecto que está relacionado ao gênero textual, isto é, uma situação que faz parte da ação social de ler uma notícia: entender quando foi publicada. A análise revela como os alunos, mediados pela professora, operam para que haja a coconstrução de sentido sobre a noção de tempo.

EXCERTO 3: “ô tia cinquenta e quatr_ IH $(0,2)$ quando ele foi pra lua minha vó tinha acabado de nascer::="

$\begin{array}{lll}56 & \text { Aline } & \begin{array}{l}\text { ((alunos conversam por } 3 \text { segundos }) \text { ) vocês conseguiram identificar? quando foi que essa } \\ \text { reportagem foi } \\ \text { publicada? }\end{array} \\ 58 & & \text { foi:::::= ((procurando no texto)) } \\ 59 & \text { João } & \text { =em mil:: novecentos e sessenta e um } \\ 1 & \text { Laís } & \text { não: }(1,0) \text { não foi }(2,0) \text { mil novecentos e sessenta e um }(0,5) \text { é a data de quando ele? } \\ 2 & \text { Aline } & \\ 3 & & \text { [[nasceu] } \\ 4 & \text { Bruno } & \text { [[viajou] só que essa reportagem }(0,5) \text { foi publicada muito tempo depois }(0,5) \text { se vocês } \\ 5 & \text { Aline } & \text { observarem direitinho perto do título vai tá assim ó }(0,5) \text { publicado em:::: } \\ 6 & & \\ 7 & & \text { doze do quatro de dois mil e onze= } \\ 8 & \text { Crianças } & \text { =em dois mil e onze }(2,0) \text { foi publicado em dois mil e on:ze }(1,0) \text { e tá dizendo no título da } \\ 9 & \text { Aline } & \text { reportagem assim }(0,5) \text { primeira viagem do homem ao espaço } \\ 10 & & \text { [faz cinquenta] anos } \\ 11 & & \text { [( } \quad \text { ] }\end{array}$


Aline

Carlos

Aline

Carlos

Aline

Carlos

Aline

Carlos

((para Laís)) -mas ela vai ele voltar depois ${ }^{\circ}$ ((de volta para a turma)) ela faz cinquenta anos <mas se essa reportagem foi publicada em dois mil e onze $(0,5)$ fez cinquenta anos em::: dois mil e onze $(0,5)<q u a n t o$ tempo será que já passou desde dois mil e onze até agora? $(1,0)$ ó dois mil e on:[:ze]

Como já foi dito anteriormente, "a significação de uma palavra é seu uso na linguagem" (WITTGENSTEIN, 1999 [1953], p. 43). Desse modo, nesse excerto, busca-se construir com os alunos os sentidos das datas que aparecem no texto.

A importância do trabalho com o gênero na aula de língua portuguesa se dá, na situação analisada, na medida em que parte de uma especificidade estrutural da reportagem, principalmente, por se tratar de um texto publicado em um site na Internet. Uma vez que textos digitais podem ser compartilhados por qualquer pessoa a qualquer hora, o fato de o leitor não estar atento à data de sua publicação pode contribuir para que haja lacunas no processo de construção de sentidos.

Isto posto, a primeira pergunta de Aline é lançada para toda a turma, na linha 56: "vocês conseguiram identificar?", no intuito de evidenciar que todos podem tentar responder à questão, nas linhas 57 e 58: "quando foi que essa reportagem foi publicada?".

Notamos o interesse de João em participar, no entanto, o prolongamento do som em sua fala - marcado na transcrição pelos dois pontos - ao tentar tomar o turno, na linha 59: "foi::::::", demonstra que o aluno ainda está a procura da resposta. Enquanto isso, Laís, na linha 1: "=em mil:: novecentos e sessenta e um", arrisca uma resposta com a primeira data que consegue localizar no texto.

Após refutar a resposta de Laís, Aline tenta dar uma pista do que aquela data significaria no texto: "não: $(1,0)$ não foi $(2,0)$ mil novecentos e sessenta e um $(0,5)$ é a data de quando ele?" (linhas 2 e 3 ), entretanto, ao mesmo tempo em que Bruno toma o turno para formular sua hipótese: "[[nasceu]" (linha 4), Aline, em fala sobreposta, na linha 5:"[[viajou]", corrige a opção de Bruno e indica em que parte do texto há pistas que Ihes ajudarão a construir o sentido: “[[viajou] só que essa reportagem $(0,5)$ foi publicada muito tempo depois $(0,5)$ se vocês observarem direitinho perto do título vai tá assim ó $(0,5)$ publicado em::.:" (linhas 5 a 7). O jogo de linguagem iniciado por Aline tem por objetivo situar a publicação da reportagem no tempo, mas os alunos ainda limitam-se a procurar quaisquer datas 
presentes na superfície do texto. A expressão "só que", após afirmar que a data apresentada por Laís se referia à viagem espacial, indica que os acontecimentos, viagem e publicação da reportagem, aconteceram em tempos distintos. A ênfase na palavra "muito", que aparece sublinhada, tem a pretensão de indicar para os alunos que houve um espaço considerável de tempo entre o feito e a publicação da notícia. Ainda em sua fala, Aline convida as crianças a buscarem no texto as pistas linguísticas, indicando onde devem procurar: "se vocês observarem direitinho perto do título", sugerindo que acompanhem a leitura: "vai tá assim ó" e mostrando, pelo prolongamento do som da última palavra, que devem completar a sentença: "publicado em:::".

Na sequência, após ler o título da reportagem, Aline tenta construir com os alunos hipóteses do tempo decorrido desde sua publicação. A fim de explorar a diferença de sentidos entre as duas datas que aparecem no texto, a saber a de publicação da reportagem e a do fato relatado por ela, após a resposta em coro das crianças, na linha 8: "doze do quatro de dois mil e onze=", Aline confirma a contribuição dos meninos e meninas repetindo e reforçando a parte final "=em dois mil e onze $(2,0)$ foi publicado em dois mil e on:ze (1,0)" (linhas 9 e 10) e segue convidando-os a acompanharem a leitura através do uso do dêitico "assim" (linha 10: "(1,0) e tá dizendo no título da reportagem assim"). Desse modo, Aline apresenta a informação trazida pelo título do texto: "ela faz cinquenta anos", em seguida, relembra a data da publicação: “<mas se essa reportagem foi publicada em dois mil e onze $(0,5)$ " e conclui "fez cinquenta anos em::: dois mil e onze $(0,5)$ ", lançando o desafio para a turma: "<quanto tempo será que já passou desde dois mil e onze até agora? $(1,0)^{\prime \prime}$. Após uma breve pausa, Aline inicia a contagem dos anos: "ó dois mil e on:[:ze]", afim de demonstrar um possível caminho para se chegar à resposta. No entanto, Carlos oferece primeiro a solução: em fala sobreposta a de Aline, na linha 22: “[qua_]", ele inicia a resposta à pergunta e, enquanto Aline ainda conta os anos: "dois mil e:: do:ze=" (linha 23) para chegar ao resultado com as crianças, ele calcula o tempo do fato relatado na reportagem, apresentando em tom de entusiasmo, marcado pela fala sublinhada, sua descoberta: "=>faz cinquenta e quatro anos $<="$ (linha 24).

Percebemos que, no trabalho com o gênero, Aline ajuda as crianças a ampliarem os sentidos acerca do que é relatado no título da reportagem, estendendo a contagem dos anos que se passaram desde o acontecimento até 2015. Observamos, na sequência, que Carlos ultrapassa essa questão quando relaciona o evento histórico a um fato de sua própria vida.

Ao modificar o jogo de linguagem, quando faz uma constatação, relacionando o tempo do feito estudado com um fato de sua própria experiência, nas linhas 26 a 27: "ô tia cinquenta e quatr_IH $(0,2)$ quando ele foi pra lua minha vó tinha acabado de nascer::=", Carlos confere um status de conversa cotidiana à situação de aula, da qual Aline também participa quando se demonstra surpresa pela declaração de Carlos: "=sua vó:?" (linha 28). "Em conversa cotidiana, repetir uma resposta com 
entonação ascendente é um dos mecanismos utilizados para acusar o recebimento de uma informação que causou uma modificação no status de conhecimento de quem formulou a pergunta (CORONA, 2009, p. 21)". A entonação ascendente na expressão destacada é marcada na transcrição pelo ponto de interrogação.

Na conversa, observamos a mudança de tópico, que passa a ser a idade da avó de Carlos: “ahã: minha vó tem cinquenta e quatro a:nos" (Carlos, linha 29).

No excerto seguinte, veremos como a imaginação continua sendo despertada pela leitura da reportagem.

\section{EXCERTO 4: “Ô TIA IMAGINA SÓ TIA se deus tá lá em cima sentado aí chega um negócio desse lá”}

\begin{tabular}{|c|c|c|}
\hline 36 & Aline & ele falou que a terra era azul por que ele falou que a terra era azul?= \\
\hline 37 & & \\
\hline 38 & Carlos & =porque tem muita água \\
\hline $\begin{array}{l}39 \\
40\end{array}$ & Aline & $\begin{array}{l}\text { porque o que ele conseguiu ver só água e olhei para todos os lados e não vi Deus }(0,5) \text { por } \\
\text { que ele falou isso será? }\end{array}$ \\
\hline 41 & João & porque deus não tava no espaço \\
\hline $\begin{array}{l}42 \\
43\end{array}$ & Aline & $\begin{array}{l}\text { é:: né: a gente tem a impressão de que deus mora no céu? aí quando a gente vai pro } \\
\text { espaço e não vê deus= }\end{array}$ \\
\hline 44 & Bruno & =então ele não tá no céu ué \\
\hline 45 & Alex & ele mora no céu( )= \\
\hline 46 & Aline & =mas não nesse espaço físico que está lá em cima \\
\hline $\begin{array}{l}47 \\
48\end{array}$ & Carlos & Ô TIA IMAGINA SÓ TIA se deus tá lá em cima sentado aí chega um negócio desse lá \\
\hline 49 & Aline & não é::: imagina se ele encontra e dá de cara= \\
\hline 50 & Alex & tia com certeza [( $)]$ \\
\hline 51 & Carlos & [caraca tia] eu dou um infarto \\
\hline 52 & Camila & ele tá no céu não no espaço \\
\hline 53 & Aline & não no espaço NE \\
\hline 54 & Alex & tia tia tia ( ) \\
\hline 55 & Carlos & ( ) tia não tem problema se eu morrer já vou tá no céu \\
\hline 56 & Aline & >já vai tá no lugar certo \\
\hline
\end{tabular}

No jogo de linguagem que desencadeia essa situação, as pistas que o texto oferece permitem que os alunos reflitam sobre a construção do sentido do texto e sobre uma questão que faz parte de suas vidas fora da escola - a crença em Deus -, e, ainda, mostra como eles relacionam esse conhecimento aos novos construídos na interação durante a leitura.

Aline medeia a interação entre as crianças e o texto a fim de que eles construam hipóteses acerca das falas de Yuri Gagarin, mencionadas na reportagem. Nas linhas 36 e 37: "ele falou que a terra era azul por que ele falou que a terra era azul?=", busca-se uma explicação acerca da cor atribuída ao planeta e tem-se apenas a colaboração de Carlos: "=porque tem muita água" (linha 38), que consegue fazer a associação da cor azul à água existente na superfície do planeta. Quem responde à próxima pergunta: “olhei para todos os lados e não vi Deus(0,5) por que ele falou isso será?" (linhas 39 e 40), 
sobre a outra frase de Gagarin, é João: "porque deus não tava no espaço" (linha 41), desencadeando uma nova discussão.

A sequência seguinte revela como o trabalho de leitura desperta a imaginação. A partir da resposta de Aline a João: "é:: né: a gente tem a impressão de que deus mora no céu? aí quando a gente vai pro espaço e não vê deus=" (linhas 42 e 43), Bruno manifesta sua conclusão: "=então ele não tá no céu ué" (linha 44), que vai de encontro ao pensamento de Alex: "ele mora no céu( )=" (linha 45), que conta com o apoio de Aline: "=mas não nesse espaço físico que está lá em cima" (linha 46) para sustentar sua afirmação. Observamos que, na fala de Aline, ainda em resposta a João, o fragmento "a gente tem a impressão de que deus mora no céu?" pode ter provocado a conclusão de Bruno, que confunde o espaço com a ideia do céu bíblico, e Alex intervém, ratificando a existência de Deus e de sua morada no céu, em uma fala parcialmente compreendida, a qual a própria Aline conclui. Essa troca de turnos entre Aline e as crianças mostra como a coconstrução de sentidos que parte da leitura do gênero jornalístico acontece muito além da superfície textual: “o sentido não está no texto, mas se constrói a partir dele, no curso de uma interação" ( $\mathrm{KOCH}, 2014$, p. 30). O texto marca apenas a ponta do iceberg de sentidos em que podemos sustentar a coconstrução de conhecimento. Nas palavras de Koch (2014), assim como o iceberg,

todo texto possui apenas uma pequena superfície exposta e imensa área imersa subjacente. Para se chegar às profundezas do implícito e dele extrair um sentido, faz-se necessário o recurso aos vários sistemas de conhecimento e a ativação de processos e estratégias cognitivas e interacionais (p. 30).

Carlos volta a participar da discussão reforçando o uso da imaginação no processo de coconstrução de sentidos: “Ô TIA IMAGINA SÓ TIA se deus tá lá em cima sentado aí chega um negócio desse lá" (linhas 47 e 48), e é incentivado por Aline: "não é::: imagina se ele encontra e dá de cara=" (linha 49). A situação projetada por Carlos nas linhas 47 e 48 é sustentada por Aline na linha 49 e por Alex: "tia com certeza [( ) ]" (linha 50), mas não por Camila, que revida: "ele tá no céu não no espaço" (linha 52), corroborando a afirmação anterior de Alex, na linha 45. Camila se mostra defensora de uma crença e desqualifica a declaração de Carlos. Mesmo assim, Carlos continua sua situação imaginária: "( ) tia não tem problema se eu morrer já vou tá no céu" (linha 55), da qual apenas eu participo: ">já vai tá no lugar certo<" (linha 56).

É dessa forma que as crianças seguem para a atividade seguinte coconstruindo conhecimento, enquanto Aline atua como mediadora desse processo.

\section{Considerações finais}


O que se pretendeu oferecer com esta abordagem foi um mapa da coconstrução de sentidos sobre um objeto textual do gênero jornalístico usado em uma aula que despertou imaginação durante o processo de aprendizagem, conforme visto na análise dos dados.

O processo de coconstrução de sentidos revelou que, apesar de a professora - enquanto mediadora das atividades com o texto - apoiar-se por diversas vezes na forma linguística, não reduziu as atividades de leitura a exercícios de "copiar e colar", porquanto sua tarefa era auxiliar os alunos a coproduzirem significação, orientando sua imaginação e conduzindo suas aprendizagens.

Indo muito além do que preconiza a abordagem formalista de que os significados são representados pelas palavras, os conhecimentos que foram coconstruídos durante essa atividade corroboram a ideia inicial de que não se trata apenas de compreender ou interpretar as pistas textuais, uma vez que partimos da premissa de que nenhum sentido é dado previamente, mas sim, coconstruído.

Os resultados mostraram que uma proposta de aula, inspirada na arte de brincar com a produção de sentidos de um texto, conseguiu um engajamento maior das crianças; não reduziu a prática de leitura a exercícios de "copiar e colar", e permitiu a coprodução de significados, orientando a imaginação de modo a estimular o processo de ensino e aprendizagem.

The co-construction of meanings and the imagination in reading practices based on textual genres: the analysis of a proposal for the 4th year of elementary education

\begin{abstract}
Based on a pragmatic perspective of language, inspired by the theories of literacy (KLEIMAN, 2007; STREET, 2014 [1995]) and textual genres (MARCUSCHI, 2008; BHATIA, 2001 [1997]; BAKHTIN, 2011; SCHNEUWLY e DOLZ, 2011 [2004]); this article intends to promote an analysis of talk-in-interaction in classroom. The reading activity developed in class made it possible to investigate how the process of co-construction of meanings from a text of the journalistic genre activates the imagination and expands the work with the written text. The results showed that a class proposal, inspired by the art of playing with the production of meanings of a text, achieved greater engagement of children; did not reduce the reading practices to "copy and paste" exercises, and allowed the co-production of meanings, guiding the imagination in order to stimulate the teachinglearning process.
\end{abstract}

Keywords: Talk-in-interaction. Co-construction of knowledge. Imagination. Textual genres. Literacy. 


\section{Referências}

BAKHTIN, Mikhail Mikhailovitch. Estética da criação verbal. Trad. Paulo Bezerra. 6ạ ed. - São Paulo: Editora WMF Martins Fontes, 2011.

BHATIA, Vijay K.. Análise de gêneros hoje. Revista de Letras, vol. 12, n. ㅇ 23, p. 102-115. jan./dez. 2001. Trad. Benedito G. Bezerra.

BIASI-RODRIGUES, B.; BEZERRA, B. G. Propósito comunicativo em análise de gênero. Linguagem em (dis)curso, v. 12, n. 1, p. 231-249, jan./abr. 2012.

BRONCKART, Jean-Paul. Desarrollo del lenguaje y didáctica de las lenguas. Buenos Aires: Miño y Dávila, 2010 [2007].

CAVALCANTE, Mônica Magalhães. Os sentidos do texto. São Paulo: Contexto, 2014.

CORONA, Márcia Del. Fala-em-interação cotidiana e fala-em-interação institucional: uma análise de audiências criminais. In.: Análises de fala-em-interação institucional: a perspectiva da Análise da Conversa Etnometodológica. Campinas, SP: Mercado das Letras, 2009, p. 13-44.

DOLZ, Joaquim; SCHNEUWLY, Bernard. Os gêneros escolares - das práticas de linguagem aos objetos de ensino. In: SCHNEUWLY, B; DOLZ, J. et alii. Gêneros orais e escritos na escola. 3ạ ed. Trad.e org. R. Rojo e G. S. Cordeiro. Campinas: Mercados das Letras, 2011 [2004], p. 61-78.

. O oral como texto: como construir um objeto de ensino. In: SCHNEUWLY, B; DOLZ, J. et alii. Gêneros orais e escritos na escola. $3^{a}$ ed. Trad.e org. R. Rojo e G. S. Cordeiro. Campinas: Mercados das Letras, 2011 [2004], p. 125- 155.

GARCEZ, Pedro M. Formas institucionais de fala-em-interação e conversa cotidiana: elementos para a distinção a partir da atividade de argumentar. Palavra. Rio de Janeiro, v. 8, p. 54-73, 2002.

. A organização da fala-em-interação na sala de aula: controle social, reprodução de conhecimento, construção conjunta de conhecimento. Calidoscópio. vol. 4, n. 1, p. 66-80, jan.-abr., 2006. Disponível em: <revistas.unisinos.br/index.php/calidoscopio/article/view/5988/3166> Acesso em fev. 2016.

GLOCK, Hans-Johann. Dicionário Wittgenstein. Trad. Helena Martins. Rio de Janeiro: Jorge Zahar, 1998.

HARRÉ, R.; GILLETT, G. A mente discursiva: os avanços na ciência cognitiva. Trad. Dayse Batista. Porto Alegre: Artes Médicas Sul, 1999.

JEFFERSON, Gail. Glossary of transcript symbols with an introduction. In: LERNER, Gene H. Conversation Analysis: studies from the first generation. Amsterdan/Philadelphia: Jonh Benjamins Publishing Company, 2004.

KLEIMAN, Angela B. Letramento e suas implicações para o ensino de língua materna. Revista Signo. Santa Cruz do Sul, v. 32 n 53, p. 1-25, dez 2007.

$\mathrm{KOCH}$, Ingedore Grunfeld Villaça. O texto e a construção de sentidos. 10 a ed. São Paulo: Contexto, 2014 [1997]. 
; CUNHA-LIMA, Maria Luiza. Do cognitivismo ao sociocognitivismo. In: MUSSALIN, Fernanda; BENTES, Anna Christina. (Org.) Introdução à linguística: fundamentos epistemológicos. vol. 3. São Paulo: Editora Cortez, 2011. p. 251-300.

; ELIAS, Vanda Maria. Ler e compreender os sentidos do texto. 3a ed. São Paulo: Contexto, 2014.

MARCUSCHI, Luiz Antônio. Cognição, linguagem e práticas interacionais. Rio de Janeiro: Lucerna, 2007.

Produção textual: análise de gêneros e compreensão. São Paulo: Parábola Editorial, 2008

MARTINS, Helena. Sobre a estabilidade do significado em Wittgenstein. Revista Veredas, Juiz de Fora, v. 4, n 2, p. 19 a 42, 2000. Disponível em: <http://www.ufjf.br/revistaveredas/edicoes/20002/volume-4-n-2-2000/>. Acesso em: set. 2016.

.Três caminhos na filosofia da linguagem. In: MUSSALIN, Fernanda; BENTES, Anna Christina. (Org.) Introdução à linguística: fundamentos epistemológicos. vol. 3. São Paulo: Editora Cortez, 2011.

ROJO, Roxane. Pedagogia dos multiletramentos: diversidade cultural e de linguagens na escola. In: ROJO, Roxane; MOURA, Eduardo. (Orgs.) Multiletramentos na escola. São Paulo: Parábola Editorial, 2012, p. 11-31.

SACKS, H.; SCHEGLOFF, E.; JEFFERSON, G. Sistemática elementar para a organização da tomada de turnos para a conversa. Veredas. Juiz de Fora, v.7, n 1 e n 2, p.9-73, jan./dez. 2003.

SCHNEUWLY, Bernard. Gêneros e tipos de discurso: considerações psicológicas e ontogenéticas. In: SCHNEUWLY, B; DOLZ, J. et alii. Gêneros orais e escritos na escola. 3a ed. Trad.e org. R. Rojo e G. S. Cordeiro. Campinas: Mercados das Letras, 2011 [2004], p. 19- 34.

SOLÉ, Isabel. Estratégias de leitura. Porto Alegre: Artmed, 1998.

STREET, Brian. Letramentos sociais: abordagens críticas do letramento no desenvolvimento, na etnografia e na educação. Trad. Marcos Bagno. 1a ed. - São Paulo: Parábola Editorial, 2014.

WITTGENSTEIN, Ludwig. Investigações Filosóficas. Trad. José Carlos Bruni. São Paulo: Editora Nova Cultural, 1999 [1953]. 